\title{
Bloqueo peridural lumbar con bupivacaína y sulfato de magnesio para cirugía ortopédica en niños de 2 a 6 años de edad
}

\author{
Salinas Memije AJ.1,2, Lozano Camacho SM. ${ }^{1}$, Vázquez Cortés ML. ${ }^{1}$, Hernández Lara González FE. ${ }^{1}$ \\ 1 Hospital para el Niño Poblano, Puebla, México. \\ 2 Iguala.
}

Introducción: El bloqueo neuroaxial sigue siendo piedra angular de la anestesia regional pediátrica como control del dolor perioperatorio, mejorando la respuesta endócrina ante el estrés quirúrgico. Un tercio de cirugías en niños son por padecimientos ortopédicos. El sulfato de magnesio (MgSO4) es una molécula imprescindible en el contexto anestésico, participa regulando la homeostasis y a nivel peridural potencia la acción de anestésicos locales sin efectos adversos importantes, retrasa el inicio del dolor postoperatorio y reduce la cantidad total de analgésicos requeridos.

Objetivo: Determinar las diferencias entre la asociación bupivacaína-sulfato de magnesio y bupivacaína sin aditivos para bloqueo neuroaxial en pacientes de 2 a 6 años de edad sometidos a cirugía de miembros inferiores en el Hospital para el Niño Poblano.

Material y Métodos: Estudio analítico, comparativo, longitudinal, monocéntrico y retrospectivo. Dos grupos, 18 pacientes cada uno; anestesia inhalatoria más bloqueo peridural con bupivacaína $0,5 \% 3 \mathrm{mg} / \mathrm{kg}$ (grupo B) o bupivacaína $0,5 \% 3 \mathrm{mg} / \mathrm{kg}$ más MgSO4 a $3 \mathrm{mg} / \mathrm{kg}$ (grupo B-SM). Se valoró dolor postoperatorio (escala de Wong Baker), bloqueo motor residual (escala Bromage) y requerimiento de rescate analgésico.

Métodos estadísticos: Medidas de tendencia central; prueba de ANOVA y ?2.

Descripción de resultados: La percepción de dolor postoperatorio fue menor en la medición inicial para el grupo BSM (el 41,7\% registró valor de 0) comparado con el grupo B. Una tendencia similar se observó a los 15, 30 y 60 min, $(\mathrm{p}<0,01)$. Respecto a rescate analgésico, el grupo B se requirió más rescates $(30,6 \%)$ que para el grupo BSM (19,4\%). En la evaluación de bloqueo motor con escala de Bromage, se encontraron diferencias significativas al ingreso a recuperación y a los 60 minutos $(\mathrm{p}<0,05)$, teniendo bloqueo residual más profundo los pacientes del grupo B-SM.

Conclusiones: Los pacientes con bloqueo peridural con bupivacaína y sulfato de magnesio tienen mejor nivel analgésico postoperatorio, mayor profundidad de bloqueo motor residual y menor requerimiento de rescate analgésico en la UCPA.

https://doi.org/10.25237/congresoclasa2019.24 